\title{
THE EFFECT OF METAMORPHIC ANNEALING AND BETA- IRRADIATION ON OPTICAL PROPERTIES OF TYPE IaA DIAMONDS
}

\author{
Yelisseyev AP ${ }^{1}$, Afanasiev VP ${ }^{1}$, Kopylova MG $^{\mathbf{2}}$, Bulbak TA ${ }^{\mathbf{1}}$ \\ ${ }^{1}$ Sobolev Institute of Geology and Mineralogy, Novosibirsk, Russia \\ ${ }^{2}$ University of British Columbia, Vancouver, Canada
}

\section{INTRODUCTION}

It has been proposed recently that low-grade metamorphism and associated crustal processes shift luminescence of diamonds to longer wavelengths thus providing a tool for reconstructing the geological history of diamond in the crust (Bruce et al, 2011). This conclusion was reached based on studies of diamonds from metasedimentary conglomerates of Wawa (Canada). The diamonds demonstrate the low-temperature photoluminescence $(\mathrm{PL})$ of $\mathrm{H} 3, \mathrm{NV}^{0}$ and $\mathrm{NV}^{-}$centers when excited with the $488 \mathrm{~nm}$ radiation of $\mathrm{Ar}^{+}$laser. It was further concluded that Type Ia diamonds from rocks metamorphosed in the greenschist facies cathodoluminesce green, yellow and red due to irradiation of diamonds in the upper crust followed by annealing at relatively low pressures and temperatures $\left(2-10 \mathrm{~kb}, 350-520{ }^{\circ} \mathrm{C}\right.$ ) (Bruce et al, 2011). The goal of the present paper is to test this conclusion experimentally.

\section{SAMPLES}

Three diamond suites (called Groups 1, 2 and 3), each containing 5 natural type IaA stones of different morphology (octahedral, cuboid and complex shape) from the Internatsional'naya pipe in Yakutia were used for experiments. IR absorption spectra of all these diamonds were dominated by the main band at $1282 \mathrm{~cm}^{-1}$ and a shoulder at $1100 \mathrm{~cm}^{-1}$ related to A-defects (pairs of substitution nitrogen atoms). As calculated from the IR absorption (Zaitsev, 2001), N concentration varied from 150 to $1800 \mathrm{ppm}$. The nitrogen aggregated as A-centers (pairs of $\mathrm{N}$ atoms), with concentrations of single substitutional $\mathrm{N}$ (Ccenters) and groups of four N (B-centers) being below detection limit of $20 \mathrm{ppm}$.

\section{EXPERIMENTS}

Experiments were carried out for $5 \mathrm{~h}$ at $500^{\circ} \mathrm{C}, 0.4$ GPa on an UVD-1000 apparatus, in a Tuttle tube reactor with a water-cooled shutter, connected with a hydraulic press (the Sobolev Institute of Geology and Mineralogy, Novosibirsk). The design of the apparatus makes it possible to maintain high pressure independently of temperature. Three gold tubes with sizes $24 \times \varnothing 5 \times 0.1 \mathrm{~mm}^{3}$ were filled with diamonds, fine powder of kimberlite N1 from the Nyurba pipe (Yakutia) tube and bi-distilled water and were placed inside the external gold ampoule $50 \times \varnothing 10 \times 0.2 \mathrm{~mm}^{3}$ in size. The bi-distlled water was used as the pressure medium. The ends and sides of each tube with diamonds were cogged tightly but not sealed. To exclude a reaction of kimberlite with water, the water content was kept low, at 26 wt. \% of the total kimberlite+diamonds weight. To minimize the presence of air inside the experimental charge, the external ampoule was completely filled with kimberlite and welded while being cooled with liquid nitrogen. Pressure was controlled with high accuracy, down to $\pm 2 \mathrm{MPa}$ by a manometer connected with the Tuttle tube reactor via a bellow valve. The manometer and the reactor were disconnected during experiments by a valve with a hydraulic drive to a locking needle. The reactor was isobarically heated and quenched to preclude the depressurization of the gold tube, particularly when the water vapor turns into a supercritical fluid. The tube was gradually (over $2 \mathrm{~h}$ ) heated and pressurized, kept at the constant high pressure and temperature for $5 \mathrm{~h}$, and cooled in the furnace for $12 \mathrm{~h}$. The experimental temperature was measured by an armored capillary chromel-alumel thermocouple, which was inserted into the high-pressure vessel through the gasket in the valve. The temperature was measured very accurately to $\pm 2^{\circ} \mathrm{C}$ and maintained to $\pm 5^{\circ} \mathrm{C}$ during the experiments by a temperature operated controller PIT-3B. 


\section{$10^{\text {th }}$ International Kimberlite Conference, Bangalore - 2012}

All diamonds (Group 1, 2 and 3) were subjected to high-pressure, high-temperature experiments as described above, but Group 2 and 3 diamonds were irradiated prior to the experiments. The experimental pressure, temperature and the presence of hydrous fluid were chosen to reproduce conditions common in the metamorphic greenschist facies $\left(2-10 \mathrm{~kb}, 350-520{ }^{\circ} \mathrm{C}\right)$ and will be called "metamorphic annealing" thereafter. The irradiation was done with fast 3.5 $\mathrm{MeV}$ electrons from a linear electron accelerator (the Institute of Chemical Kinetics and Combustion SB RAS) at two different fluences, $10^{17}$ (Group 2 samples) and $10^{18} \mathrm{~cm}^{-2}$ (Group 3 samples) respectively. The irradiation imitated the beta-decay common for the most abundant radioactive isotopes of the upper crust (Bruce et al., 2011). Color and photoluminescence of the diamonds were examined under optical microscope; absorption and PL spectra at $365 \mathrm{~nm}$ excitation were recorded at $80^{\circ} \mathrm{K}$ at each stage of the experimental treatment. Absorption and PL spectra were obtained at the spectra resolution equal to $1.5 \mathrm{~nm}$.

\section{RESULTS}

For all 3 groups of diamonds, irradiation and metamorphic annealing did not affect IR absorption spectra of the diamonds indicating no measurable changes in the $\mathrm{N}$ aggregation state.

For Group 1 samples, metamorphic annealing changed optical absorption at short wavelengths, in the UV to visible region (Fig. 1). The type IaA diamonds are transparent at $\lambda>300 \mathrm{~nm}$ but many samples show also a weak absorption at wavelengths $<700 \mathrm{~nm}$, which may be associated with single nitrogen (center C) not detected by IR spectroscopy, or with absorption of dangled bonds in dislocations (Zaitsev, 2001). Some crystals (Fig. 1a) with the highest $\mathrm{N}$ content demonstrate absorption in the N3 system with the zero-phonon line (ZPL) at $415.2 \mathrm{~nm}$ associated with the $\mathrm{N}_{3} \mathrm{~V}$ complex, where $\mathrm{N}$ is nitrogen atom and $V$ is a vacancy (Zaitsev, 2001). Metamorphic annealing causes intensity of the broad band absorption at $\lambda<700 \mathrm{~nm}$ decrease 2-3 times (Fig.1). The N3 absorption, however, remains unaffected.

After irradiation, intense GR1 and ND1 systems with ZPLs at 741 and $394 \mathrm{~nm}$, respectively, appear in absorption spectra of Group 2 and 3 diamonds (Fig. 2). This attests to generation of neutral $\left(\mathrm{V}^{0}\right)$ and negatively charged $\left(\mathrm{V}^{-}\right)$vacancies in the diamond lattice. Further metamorphic annealing weakens the GR1 and ND1 absorption. After annealing new vibronic systems with 595 and $503.2 \mathrm{~nm}$ appear. The first is ascribed to a $\mathrm{N}^{-} \mathrm{V}$ complex whereas the second is a well known $\mathrm{H} 3\left(\mathrm{~N}_{2} \mathrm{~V}_{2}\right.$ center $)$. Furthermore, irradiation produces weaker ZPLs at $507 \mathrm{~nm}$ and $439 \mathrm{~nm}$ associated with some nitrogen-vacancy complexes (Zaitsev, 2001). All changes described above become more pronounced as the irradiation dose increases.
Similar to absorption of visible light, photoluminescence of diamond is also significantly affected
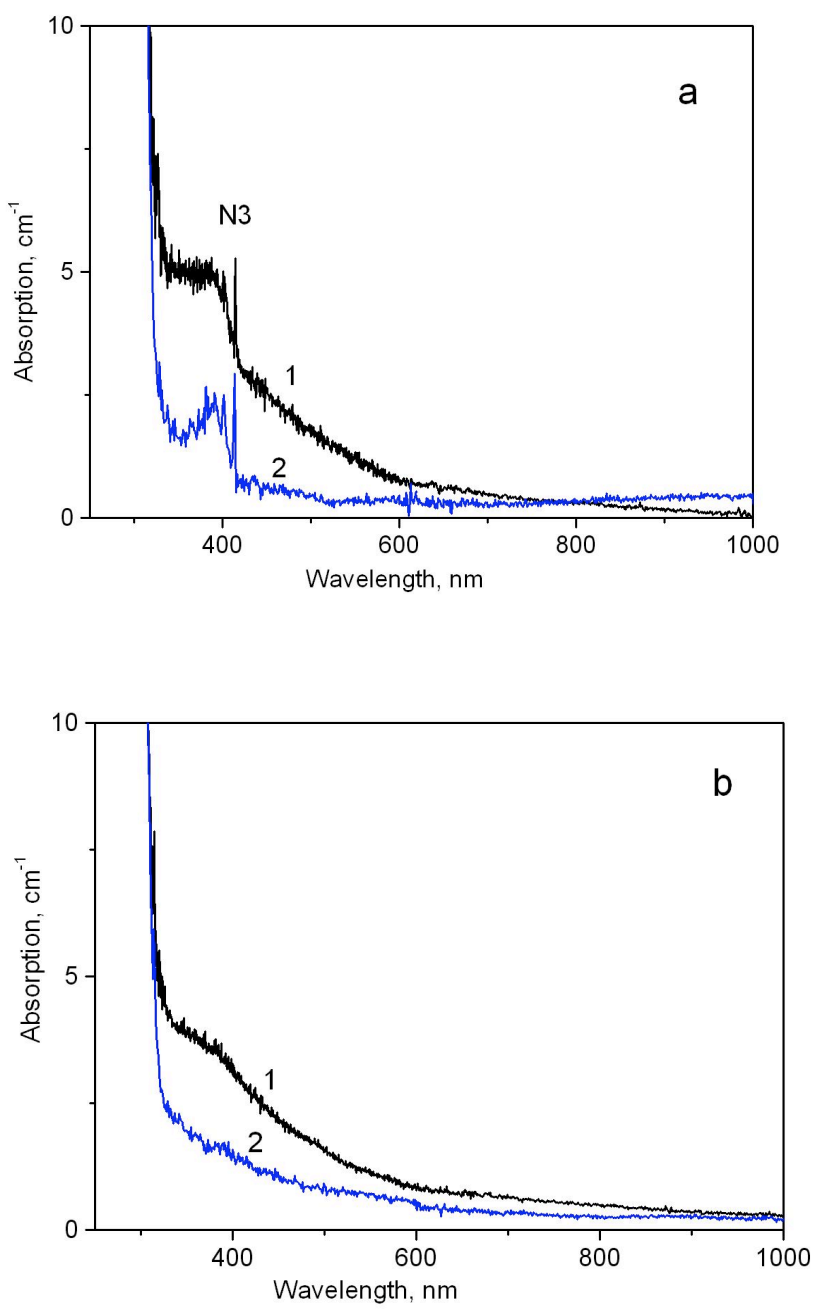

Fig. 1. Absorption spectra at $80 \mathrm{~K}$ of Group 1 natural diamonds \# 411 (a) and \# 3110 (b) of group 1 before (1) and after metamorphic annealing (2).

by irradiation and metamorphic annealing. This effect plays out differently for diamonds with different content of nitrogen A-centers, as illustrated by spectra of two diamonds, sample \#711 with concentration of nitrogen Acenters $640 \mathrm{ppm}$ (Fig. 3a) and sample \#713 with concentration of nitrogen A-centers 320 ppm (Fig. 3b). In PL spectra of natural diamonds before treatment one can usually see a broad band with a maximum near $435 \mathrm{~nm}$, which is known as A-band (Zaitsev, 2001). This PL is associated with dislocations and is particularly strong in Type IIa (low nitrogen) diamonds, whereas nitrogen quenches this emission. After irradiation and metamorphic annealing, the $\mathrm{H} 3$ system appears in PL spectra of low-N diamonds, as exemplified by sample \#713 (Fig. 3b). By 
contrast, diamonds with higher concentration of A-centers (Fig. 3a) show not only the H3 system, but also N3 and $\mathrm{NV}^{0}$ systems with ZPLs at 415.2 and $575 \mathrm{~nm}$, respectively. We conclude that the change in the diamond luminescence after irradiation and metamorphic annealing relates to the emergence of the intense green emission from the strong H3 system.
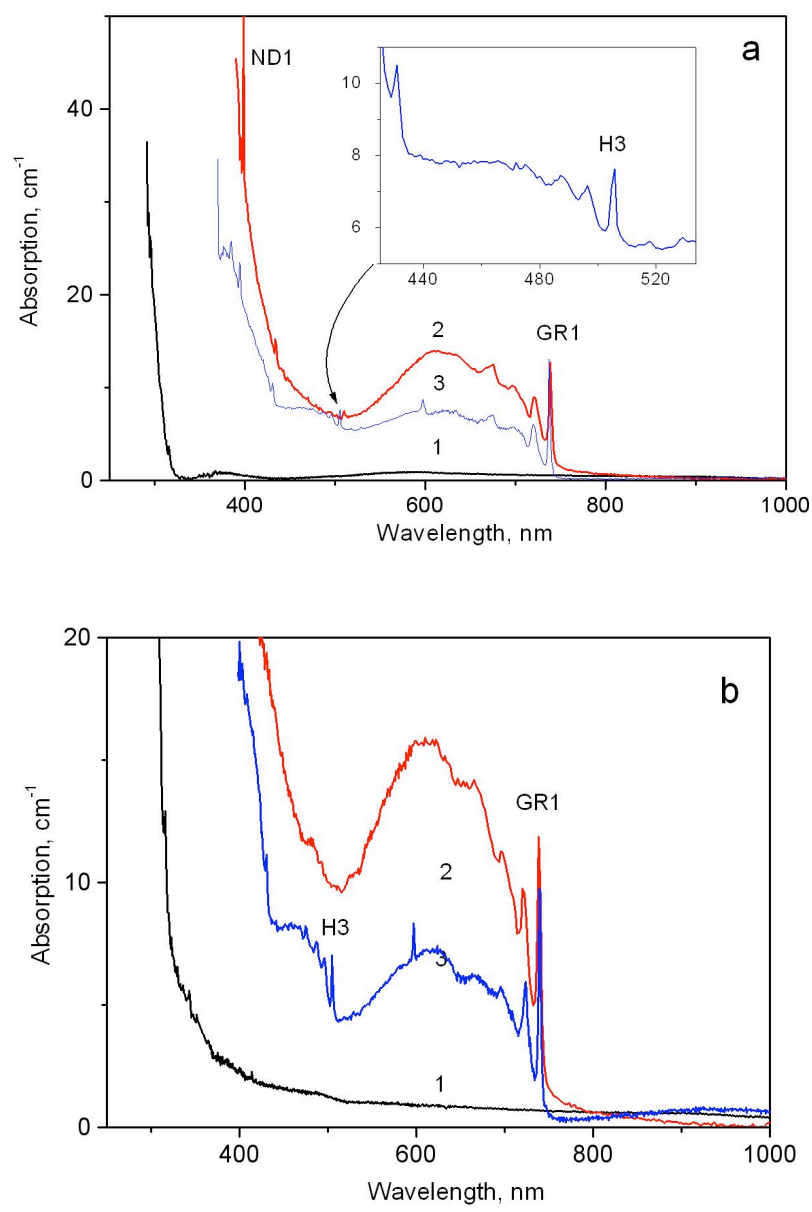

Fig. 2. Absorption spectra at $80 \mathrm{~K}$ of Group 2 and 3 samples ND\# 3117 (a) and ND \#3119 (b) before treatment (1), after irradiation (fluency $10^{18} \mathrm{~cm}^{-2}, 2$ ) and after metamorphic annealing (3).

\section{DISCUSSION}

Our results suggest that metamorphic annealing significantly reduces absorption of light in the 300 to $700 \mathrm{~nm}$ range and, as a result, reduces intensity of blue-green colour induced by irradiation of diamond. It is surprising that the effect is very strong in IaA-type diamonds at such low pressure and temperature parameters (5h annealing at 0.4 $\mathrm{GPa}, 500^{\circ} \mathrm{C}$ ). This has important practical applications. We ascribe absorption in the 300 to $700 \mathrm{~nm}$ range to the presence of dislocations and propose that metamorphic annealing affects their state in some way.

Although the absorption spectrum in the 300 to 700 $\mathrm{nm}$ range is very similar to that of nitrogen C-centers, we do not interpret the observed absorption as associated with single substitutional N (C-centers) for two reasons. First, Ccenters are known to be unaffected by high-pressure annealing at temperatures as low as $500^{\circ} \mathrm{C}$. Secondly, Ccenters were not created by metamorphic annealing in our experiments. $\mathrm{C}$-centers have been found in studied diamonds only after a combined treatment of irradiation and metamorphic annealing. The evidence for this is nitrogenvacancy complexes NV in recorded absorption (Fig. 2) and PL spectra (Fig. 3).

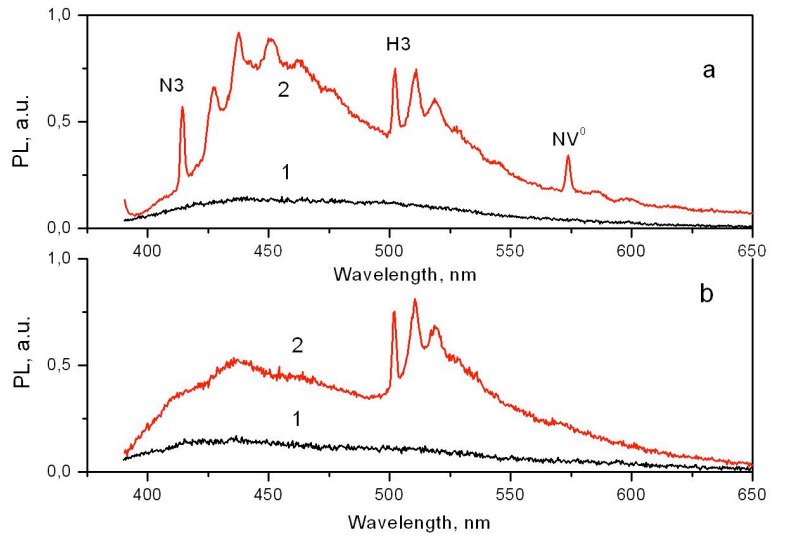

Fig.3. Photoluminescence spectra of ND\#711 (a) and \#713 (b) at $80 \mathrm{~K}$ before treatment (1) and after irradiation and further metamorphic annealing (2).

Irradiation of type IaA diamonds produces a significant amount of neutral and negatively charged vacancies $\left(\mathrm{V}^{0}, \mathrm{~V}^{-}\right)$. As follows from absorption and $\mathrm{PL}$ spectra, metamorphic annealing makes the vacancies mobile. They become captured by nitrogen-only defects forming new, more complex defects from $\mathrm{N}$ and vacancies. These complex defects are dominated by $\mathrm{H} 3$ centers $\left(\mathrm{N}_{2} \mathrm{~V}_{2}\right)$ observable in both absorption and PL spectra. Also present are $\mathrm{NV}$ and $\mathrm{N}_{3} \mathrm{~V}$ centers as evidenced by PL spectra (Fig. $3)$. All these complex defects are built around common Nonly defects of the crystal lattice, such as single substitutional $\mathrm{N}$ atoms (C-centers) or coupled $\mathrm{N}$ (Acenters). The original nitrogen defects are immobile at the annealing temperature of $500^{\circ} \mathrm{C}$. Preliminary irradiation is of critical importance for the above processes because it decreases the temperature at which vacancies become mobile. Without irradiation, vacancies could migrate only at much higher temperatures, $\mathrm{T} \sim 900^{\circ} \mathrm{C}$ (Collins and Kiflawi, 2009).

Comparison of our experiments on type IaA diamonds with luminescence of natural metamorphosed diamonds (Bruce et al, 2011) established some common 
patterns and some differences. In both laboratory and natural conditions, we found nitrogen-vacancy complexes $\mathrm{H} 3$ and $\mathrm{NV}^{0}$. They formed after low-energy diamond treatment (irradiation and metamorphic annealing), which causes vacancies to become mobile. The experiments could not reproduce formation of the $638 \mathrm{~nm}$ system corresponding to the $\mathrm{NV}^{-}$center, observed in natural metamorphosed diamonds (Bruce et al, 2011). In contrast to these diamonds, the observed ratio between intensities of vibronic systems is different. We explain these discrepancies by different excitation conditions $(365 \mathrm{~nm}$ $\mathrm{Hg}$ excitation in this paper and $488 \mathrm{~nm} \mathrm{Ar}^{+}$excitation by Bruce et al, (2011) for the photoluminescence spectroscopy.

\section{CONCLUSIONS}

1. Metamorphic annealing at $0.5 \mathrm{GPa}, 500^{\circ} \mathrm{C}$ makes natural type IaA diamonds more transparent, while intensity of the $\mathrm{N} 3$ absorption system remains constant.

2. Irradiation and metamorphic annealing of diamond produces intense green luminescence from the strong H3 system.

3. Our experiments confirm that electron irradiation of diamond followed by the low grade metamorphism causes vacancy migration and formation of complex nitrogen-vacancy complexes, as it has been detected in metamorphosed IaA and IaAB diamonds found in crustal rocks (Bruce et al, 2011).

\section{REFERENCES}

Bruce L.F., Kopylova M.G., Longo M., Ryder J., Dobrzhinetskaya L.F. (2011) Luminescence of diamonds from metamorphic rocks, American Mineralogist, 96, 14-22.

Zaitsev, A. (2001) Optical properties of diamond: A data handbook, 502 p., Springer Verlag, Berlin.

Collins AT, Kiflawi I. (2009) The annealing of radiation damage in type Ia diamonds, J. Phys. Condensed Matter, 21, 364209,8 . 